\section{Suicide in custody}

\author{
Case-control study \\ STEFAN FRUEHWALD, TERESA MATSCHNIG, FRANZ KOENIG, \\ PETER BAUER and PATRICK FROTTIER
}

\author{
Background Few risk factors and \\ indicators of vulnerability for suicide in \\ custody are known so far.
}

\begin{abstract}
Aims A case-control study was conducted to investigate the relevance of criminal history, psychiatric morbidity and social integration to suicide in prison.
\end{abstract}

Method For every suicide that occurred in an Austrian correctional institution between 1975 and 1999, two controls matched for correctional institution, gender, nationality, age, custodial status and time of admission were selected. Psychiatric characteristics, previous suicidal behaviour, criminal history and indicators of social integration were compared.

Results Of 250 recorded suicides, 220 personal files were available and matched to 440 controls. The most important predictors for suicide in custody were a history of suicidality (status following attempted suicide and suicide threat), psychiatric diagnosis, psychotropic medication, a highly violent index offence and single-cell accommodation.

Conclusions A significant finding is the importance of suicidal behaviour as an indicator of risk of suicide in correctional institutions, which until now has been a matter of debate. This study demonstrates the need for staff to take suicidal behaviour as seriously in custodial settings as in any other circumstances.

Declaration of interest None.
Suicide rates in prisons exceed the rates in the general population worldwide (Joukamaa, 1997; Fruehwald et al, 2002a,b; Landsberg $\&$ Morschauser, 2003). Risk factors for suicide in custody include long sentences after highly violent crimes (DuRand et al, 1995), overcrowding (Marcus \& Alcabes, 1993), isolation (Frottier et al, 2001), psychiatric disorders (Marcus \& Alcabes, 1993; Bogue \& Power, 1995; Joukamaa, 1997), and alcohol and drug misuse (Backett, 1987; Dooley, 1990). The validity of risk factors is methodologically questionable if the suicide group is studied in isolation. To establish vulnerability profiles, risk factors and protective factors reliably, case-control studies are needed. To our knowledge, no such study has been reported so far. We therefore conducted a case-control study including matched controls for each suicide in custody over a 25 -year period, to identify characteristics of inmates that were unequally distributed between those who completed suicide and those who survived custody.

\section{METHOD}

\section{Cases}

Every suicide occurring in one of the 29 correctional institutions in Austria has to be reported to the Prison Department of the Ministry of Justice in Austria (population 8 million). These documents report personal and criminal characteristics of the inmate and the circumstances, time and method of suicide. This list of all suicides, which is the basis of the official documentation of the Ministry of Justice, was our primary source of information for the period 1 January 1975 to 31 December 1999. Second, all personal records of all known suicide cases were taken from each prison's archive. Our study included only suicides for which the personal records were available. Third, each of the 29 correctional facilities in Austria was visited and all personal files of cases of unnatural death or serious medical condition were scrutinised to check whether some cases of suicide had been neglected or overlooked by the official statistics. In one case a man had survived a severe suicide attempt and died in the intensive care unit of the local general hospital some weeks later, after he had been 'released for reason of serious medical illness' by the local courts; no suicide was reported to the Ministry of Justice afterwards. This case was included in the study. We did not include any cases with an open verdict.

\section{Controls}

For each suicide case that had been identified, two matched controls were collected to increase the power of the study (this was just manageable with the available resources). In addition to common matching parameters (age, gender, nationality), we matched for custodial institution, custodial status (pre-trial, sentenced, mentally disordered) and time of admission, to control for environmental factors that might change over time. All 29 correctional facilities in Austria were visited and the personal files of the matched controls were collected. We consulted the records of index assessments at each institution to find the admission of the person who had committed suicide (the case). We then looked for inmates of the same age, gender, nationality and custodial status (pre-trial, sentenced, mentally disordered), who had been admitted at around the time of the admission date of the suicide case. The personal files of two prisoners whose admission dates were closest to that of the suicide case were included. If we were unable to find a personal file of someone who had been admitted to the same custodial institution within 6 months (earlier or later) of the suicide case, or whose age was within 2.5 years of the age of the case individual, or if all personal files of matching controls had already been destroyed, we took as a control the file of a prisoner admitted later. All controls were collected by a psychiatrist (P.F.), and the files of cases and controls were coded by the same researcher (S.F.).

\section{Variables}

The following variables were investigated in the files of cases and controls.

\section{Personal data}

Personal data included gender, age, nationality, marital status, number of children, 
religion, degree of professional education, occupational status and presence of tattoos.

\section{Criminological data}

We recorded custodial status (pre-trial, sentenced or not guilty for reason of insanity); number of previous convictions; number of previous incarcerations; types of previous offences; and nature of last offence (property offence, level of violence (low or high), sex offence, drug-related offence, damage of property, other offence).

\section{Psychiatric characteristics}

Psychiatric characteristics noted were psychiatric assessment (contact with a psychiatrist while incarcerated); psychiatric diagnosis; psychopharmacological treatment (prescribed while incarcerated); substance misuse; previous suicide attempt; and suicide threat (coded positive if we found a remark in the medical record or in the general file).

\section{Information about incarceration}

The name of the correctional institution was recorded, together with date of admission, date of suicide, date of planned release (for sentenced offenders), visits while in custody, housing while incarcerated, working status while incarcerated and contact with significant others while incarcerated.

\section{Statistics}

To check for differences between cases and controls, univariate analyses were performed using Fisher's exact tests for categorical variables and Wilcoxon two-sample tests for continuous variables. This was done for the whole sample and separately for the three subgroups for custodial status.

To explain suicide in prison, stepwise unmatched logistic regression was used because of the large number of missing values. In all multivariate analyses the matching variables were kept fixed in the models. In a first analysis (model 1) all variables that had a $P$ value less than 0.01 in at least one of the four univariate comparisons cases $v$. controls were considered as independent variables to model the odds for suicide in custody. The significance level for entering the stepwise logistic model was set to $P=0.05$. In the stepwise logistic regression all individuals with missing values in at least one of the influence factors were dropped. So in a further nonstepwise final analysis, only the variables selected by model 1 and the matching variables were used as independent variables, to reduce the number of missing cases (model 2). For the final analysis, odds ratios and corresponding $95 \%$ confidence intervals were calculated. We also performed matched conditional logistic regression analyses (SAS procedure PHREG with a STRATA variable), which essentially confirmed the results when convergence of the model could be achieved. We used the SAS statistical software system (version 8.1, SAS Institute Inc., Cary, NC, USA) for the calculations.

\section{RESULTS}

Descriptive statistics for all six matching variables are reported in Table 1 . The univariate comparisons between cases $(n=220)$ and controls $(n=440)$ for the whole sample and within the subgroups are shown in Table 1. The variables in bold type are those included in the subsequent multivariate analyses, together with the matching variables.

\section{Overall analysis for the whole sample}

Performing the stepwise logistic regression for the whole sample, 265 (out of 660) observations were deleted because of missing values for explanatory variables. In model 1 the seven explanatory variables entered were 'known suicide attempt', 'single-cell accommodation', 'psychiatric diagnosis', 'last offence: high level of violence', 'psychiatric medication', 'last offence against property' and 'suicide threat'. However, before interpreting these significant results, it has to be mentioned that the matching variables 'custodial institution' $(P=0.029)$, age $(P=0.03)$ and time of admission $(P=0.036)$ also contributed to the risk of suicide. Applying model 2 to the reduced set of influence variables selected by model 1 , custodial institution $(P=0.0086)$ and time of admission $(P=0.01)$ still remained as significant predictors. This points to an imbalance of missing values against the values of the matching variables. In fact, a systematic loss of data for the control group had to be considered: pre-trial prisoners' personal files were destroyed after a defined period, but this was not done for pre-trial prisoners who had died by suicide. The case-control ratio for this subgroup in the final model was as low as 1:1.01, whereas for sentenced prisoners the ratio was practically $1: 2$ in all the analyses. The reason why the factor 'custodial institution' shows up in the statistical analyses is that the majority of custodial institutions had occupants of only one custodial status. Ignoring the custodial institution in the multivariate analysis, the most influential matching variable remaining was custodial status. As a consequence of these imbalances for the pre-trial group, we performed separate multivariate analyses for pre-trial and sentenced prisoners. The number of mentally disordered prisoners was too small for this type of multivariate analysis.

\section{Pre-trial prisoners}

Following the stepwise selection procedure, the final model using 181 observations (case-control ratio 95:86) confirmed the significant influence of the selected variables 'single-cell accommodation' $(\mathrm{OR}=19.9)$, 'last offence: high level of violence' $(\mathrm{OR}=11.9)$, 'psychiatric medication' $(O R=26.9)$ and 'known suicide attempt' $(\mathrm{OR}=17.9)$. Values of $P$, odds ratio estimates and corresponding $95 \%$ confidence intervals for this final model are reported in Table 2. The matching variable 'time of admission' became significant. This was to be expected, because for pretrial controls with an early date of admission the personal files were destroyed after a defined period.

\section{Sentenced prisoners}

In the final model a total of 252 observations (cases, 84; controls, 168) were used. The significant influence of the chosen factors 'psychiatric diagnosis' $(\mathrm{OR}=17.4)$, 'single-cell accommodation' $(\mathrm{OR}=16.9)$, 'suicide threat' $(\mathrm{OR}=53.2)$, 'last offence: high level of violence' $(O R=4.3)$ and 'psychiatric medication' $(\mathrm{OR}=5.8)$ could be reproduced (Table 3). None of the matching variables yielded a significant result. A further model was performed using length of sentence as an additional variable. For this model the variables 'psychiatric diagnosis', 'single- cell accommodation', 'suicide threat' and 'length of sentence' were selected as independent variables. The final model validated their significant influence, and none of the matching variables yielded significant results. The new variable 'length of sentence' covers that of 'last offence: high level of violence' and 
Table I Univariate comparison of cases v. controls

\begin{tabular}{|c|c|c|c|c|c|}
\hline Variable & Case & Control & Variable & Case & Control \\
\hline Matching variables & & & Criminological information & & \\
\hline Gender, $n$ & & & Number of preconvictions: mean (s.e.m.) & $6.53(0.49)$ & $6.54(0.36)$ \\
\hline Female & 6 & 12 & Previously convicted: yes/no & $156 / 47$ & $287 / 80$ \\
\hline Male & 214 & 428 & Previous incarcerations: mean (s.e.m.) & $1.98(0.23)$ & $2.44(0.19)$ \\
\hline Custodial status, $n$ & & & Previous offences: yes/no & & \\
\hline Pre-trial & 103 & 195 & Against property & $105 / 74$ & $200 / 140$ \\
\hline Sentenced & 100 & 212 & High violence*s & $31 / 144$ & $29 / 311$ \\
\hline Mentally disordered & 17 & 33 & Low violence & $86 / 90$ & $157 / 183$ \\
\hline Time of incarceration (year): mean (s.e.m.) & $1988.64(0.45)$ & $1989.04(0.31)$ & Sex offence & $15 / 154$ & $26 / 314$ \\
\hline Age, years & & & Drug-related & $21 / 148$ & $26 / 314$ \\
\hline Mean (s.d.) & $34.35(0.78)$ & $34.16(0.53)$ & Property damage & $43 / 126$ & $84 / 256$ \\
\hline Range & $14.5-72.23$ & $16.46-74.05$ & Other offence ${ }^{s}$ & $68 / 101$ & $120 / 220$ \\
\hline Number of correctional institutions & 29 & 29 & Last offence: yes/no & & \\
\hline Nationality, $n$ & & & Property offence ${ }^{p}$ & $106 / 112$ & $246 / 192$ \\
\hline Austrian & 194 & 395 & High violence*P,S & $90 / 127$ & $63 / 374$ \\
\hline Other & 26 & 44 & Low violence & $67 / 150$ & $136 / 302$ \\
\hline Personal characteristics & & & Sex offence & $17 / 200$ & $45 / 392$ \\
\hline Marital status, $n$ & & & Drug-related & $24 / 193$ & $38 / 399$ \\
\hline Single & 113 & 243 & Property damage & $13 / 204$ & $25 / 412$ \\
\hline Married & 53 & 75 & Other offence & $58 / 159$ & $|26 / 3| \mid$ \\
\hline Divorced & 46 & 88 & Visits while incarcerated: yes/no & $73 / 100$ & $192 / 166$ \\
\hline Widowed & 7 & 5 & Distance of home from prison, $n$ & & \\
\hline Married: yes/no & $53 / 166$ & $75 / 336$ & Same district & 48 & 100 \\
\hline Children: yes/no & $94 / 108$ & $129 / 218$ & $<100 \mathrm{~km}$ & 80 & 157 \\
\hline Number of children: mean (s.e.m.) & $0.84(0.08)$ & $0.72(0.06)$ & $>100 \mathrm{~km}$ in Austria & 62 & 106 \\
\hline Religion & & & Abroad & 30 & 47 \\
\hline None & 27 & 44 & Psychiatric characteristics & & \\
\hline Catholic & 165 & 319 & Psychiatric assessment $* P, S$ & $107 / 113$ & $71 / 302$ \\
\hline Protestant & 14 & 19 & Psychiatric diagnosis $* P, S$ & $88 / 132$ & $33 / 341$ \\
\hline Muslim & 8 & 19 & Psychopharmacological treatment ${ }^{* P, S}$ & $81 / 139$ & $44 / 329$ \\
\hline Other & 5 & 3 & Substance misuse*s & $117 / 103$ & $125 / 249$ \\
\hline Educational status & & & Previous suicide attempt ${ }^{* P, S, N}$ & & \\
\hline Compulsory school & 91 & 127 & Known & 108 & 40 \\
\hline Apprenticeship not finished & 51 & 100 & Unknown & 112 & 334 \\
\hline Apprenticeship finished & 69 & 173 & Suicide threat ${ }^{* P, S, N}$ & & \\
\hline Graduate & 6 & 6 & Known & 81 & 14 \\
\hline Working status before incarceration ${ }^{\mathrm{s}}$ & & & Unknown & 139 & 357 \\
\hline Unemployed & 96 & 138 & Information about incarceration & & \\
\hline Unskilled worker & 57 & 118 & Working while & $85 / 113$ & $214 / 134$ \\
\hline Skilled worker & 43 & 126 & incarcerated: yes/no & & \\
\hline Professional worker & 7 & 8 & Single-cell & $134 / 62$ & $59 / 229$ \\
\hline Retired & 15 & 22 & accommodation: ${ }^{* P, S, N}$ yes/no & & \\
\hline Tattoos: yes/no & $83 / 137$ & $132 / 235$ & Contact with significant others: yes/no & $198 / 19$ & $326 / 40$ \\
\hline
\end{tabular}

Variables in bold type were included in the multivariate analyses, together with the matching variables.

${ }^{\mathrm{N}}$, not guilty by reason of insanity; ${ }^{\mathrm{P}}$, pre-trial; ${ }^{\mathrm{S}}$, sentenced.

$* P<0.01$.

'psychiatric medication'; people whose current offence involved high levels of violence are usually sentenced to long-term imprisonment.

\section{DISCUSSION}

This study can be considered reliable and methodologically sound. Data on the deaths are reliable, since they are based on official records and verdicts, and suicide certification in Austria in general was found to have the greatest sensitivity 
Table 2 Logistic regression for pre-trial custodial status group (model 2)

\begin{tabular}{lcc}
\hline & $P$ & $\begin{array}{c}\text { Odds ratio estimate } \\
\text { OR }(95 \% \mathrm{Cl})^{\prime}\end{array}$ \\
\hline Single-cell accommodation & $<0.0001$ & $19.9(5.3-75.1)$ \\
Known suicide attempt & 0.0022 & $17.9(2.8-112.8)$ \\
Psychiatric medication & 0.0023 & $26.9(3.2-223.5)$ \\
Last offence highly violent & 0.0019 & $11.9(2.5-56.7)$ \\
\hline
\end{tabular}

I. Wald $95 \%$ confidence limits.

Table 3 Logistic regression for sentenced custodial status group (model 2)

\begin{tabular}{lcc}
\hline & $P$ & $\begin{array}{c}\text { Odds ratio estimate } \\
\text { OR }(95 \% \mathrm{Cl})^{\prime}\end{array}$ \\
\hline Psychiatric diagnosis & $<0.000 \mathrm{I}$ & $17.4(4.2-7 \mathrm{I} .7)$ \\
Single-cell accommodation & $<0.000 \mathrm{I}$ & $16.9(5.5-52.2)$ \\
Suicide threat & $<0.000 \mathrm{I}$ & $53.2(7.5-379.0)$ \\
Last offence highly violent & 0.012 & $4.3(\mathrm{I} .4-13.1)$ \\
Psychiatric medication & 0.018 & $5.8(\mathrm{I} .4-24.8)$ \\
\hline
\end{tabular}

I. Wald $95 \%$ confidence limits.

compared with other high-income countries (Rockett \& McKinley Thomas, 1999). Although the multivariate analyses had to be conducted with a sub-sample, owing to missing values in at least one of the influence factors (significant difference between cases and controls in the univariate comparisons), we can present a rich dataset of 660 individuals.

According to the logistic regression models, the most important predictors for suicide in custody were a history of suicidality (status following attempted suicide and suicide threat), a psychiatric diagnosis, psychotropic medication, a highly violent index offence and single-cell accommodation. Most of these indicators of risk have been previously identified in the scientific literature, but history of suicidality has been the subject of contradictory reports. Suicidal behaviour (suicide attempts, suicide threats, self-harm) is considered to be an important risk factor for suicidality in general (Ringel, 1969). In previous prison suicide studies, a high percentage $(43-62 \%)$ of suicides were found to be of people with a history of suicidality (Backett, 1987; Dooley, 1990; Marcus \& Alcabes, 1993; Bogue \& Power, 1995; Laishes, 1997; Fruehwald et al, 2003). Suicide attempts, suicide threats and selfharm were considered typical of the total prison population, thus having little relevance for intervention (Dooley, 1990). On the other hand, it was argued that 'a not predictable majority of inmate suicides was committed by inmates who seemingly made a rational decision not to go on living, as they did not communicate their decision to anyone. The remaining minority, which was identified to be suicidal, managed to succeed in spite of appropriate monitoring and intervention' (Laishes, 1997). More recently, it was stated that most prisoners who injure themselves many repeatedly - do not go on to kill themselves (HM Chief Inspector of Prisons for England and Wales, 1999). We think that this study demonstrates the necessity for all correctional staff to take suicidal behaviour as seriously in custodial settings as in any other circumstances. Suicidal behaviour might be an important opportunity to refer people in prison to adequate psychiatric care and to take further steps to prevent suicides.

The relevance of psychiatric morbidity as one of the main risk factors for suicide in custody is strongly confirmed by this study, as is the relevance of single-cell accommodation (Frottier et al, 2002a,b), which has to be seen as a facilitating factor rather than in any way directly causative. There were a number of further significant differences between cases and controls that have not yet been identified as risk indicators, which are covered by other factors in the multivariate analyses. Professional education and working status before and during incarceration were significantly

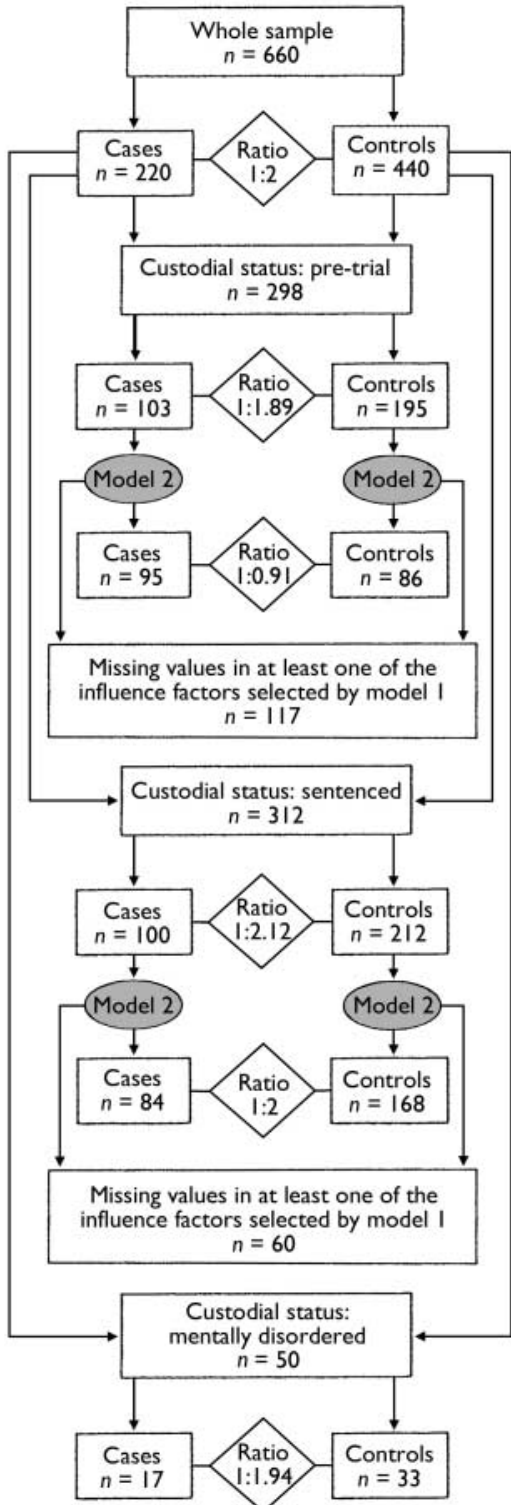

Fig. I Number of observations and case-control ratio for the whole sample and the main analyses (model 2) separated for custodial status. No multivariate analysis was performed for mentally disordered prisoners.

different between cases and controls, as were some details concerning criminological history. We think that further analyses and replication in other studies are necessary to prove the relevance of social parameters for suicide in custody - parameters that have also been mentioned in reviews by HM Chief Inspector of Prisons for England and Wales (1999) and the Scottish Prison Service (2003). Indicators of social integration could be easily used for suicide prevention purposes if asked about during admission proceedings; questions concerning working status before incarceration or professional education would be far less stigmatising than questions about psychiatric 
history and previous suicidal behaviour. However, such questions are not currently part of prison intake procedures in Austria.

The major strength of our study is its epidemiological approach, including two controls for each case of suicide over a quarter of a century. There are some limitations: we were unable to obtain all 250 personal files, as 30 files had already been destroyed. We do not think that selection bias occurred, as we obtained more than half of all files pertaining to the first few years of the period studied, over 25 years ago. A more relevant problem was that the personal files of controls tended not to contain as much valuable information as the case files. In particular, if the duration of incarceration of the people chosen as control had been short and from the viewpoint of the institution without complications, only limited amounts of information could be found in their files. Therefore, we faced a number of missing values when adhering to the matching criterion 'admission to the same institution closest to the case'. However, for sentenced prisoners the main results are based on a model in which only 60 observations were dropped, resulting in a perfect case-control ratio (i.e. 1:2).

\section{Implications of the study}

In this case-control study of 220 cases of prison suicide and 440 controls, we found that the most important predictors of suicide of pre-trial prisoners were single-cell accommodation, known previous suicide attempt, psychiatric medication prescribed while in custody, and last offence of a highly violent nature. For sentenced offenders, the most important predictors were psychiatric diagnosis, single-cell accommodation, known previous suicide attempt, last offence of a highly violent nature and psychiatric medication prescribed while in custody. Our study confirms the relevance of psychiatric diagnoses, single-cell accommodation (as a facilitating issue) and highly violent index offences to suicide in prison It highlights the importance of suicidal behaviour for suicides in correctional institutions, for which evidence has been conflicting until now.

\section{ACKNOWLEDGEMENT}

This research was supported by grant 15035 from the Austrian Science Fund.

\section{CLINICAL IMPLICATIONS}

Suicidal behaviour should be taken seriously by all staff in correctional institutions.

- Our study confirms the relevance of psychiatric diagnosis and violence of index offence as predictors of suicide in prison.

Single-cell accommodation is relevant as a facilitating factor.

\section{LIMITATIONS}

- Personal files of controls tended to contain less information than the case files.

Some personal files for controls with early admission dates had been destroyed.

Fur ther research is needed into the relevance of social parameters to suicide in custody.

STEFAN FRUEHWALD, MD, Division of Social Psychiatry, Department of Psychiatry, Medical University of Vienna, Vienna, Caritas St Poelten, St Poelten; TERESA MATSCHNIG, MD, Community Mental Health Services, Caritas St Poelten, St Poelten; FRANZ KOENIG, PETER BAUER, MD, Department of Medical Statistics, Medical University of Vienna, Vienna; PATRICK FROTTIER, MD, Justizanstalt Wien-Mittersteig, Vienna, Austria

Correspondence: Stefan Fruehwald, MD, Community Mental Health Services, Caritas St Poelten, Dr Karl Renner Promenade 12, A-3100 St Poelten, Austria. Tel: +436991063 0808; fax: +43 2742 84139; e-mail: psd.fruehwald@stpoelten.caritas.at

(First received 6 November 2003, final revision I June 2004, accepted 26 June 2004)

\section{REFERENCES}

Backett, S. A. (1987) Suicide in Scottish Prisons. British Journal of Psychiatry, I5I, 218-221.

Bogue, J. \& Power, K. (1995) Suicide in Scottish prisons, 1976-1993. Journal of Forensic Psychiatry, 6, 527-540.

Dooley, E. (1990) Prison suicide in England and Wales, 1972-87. British Journal of Psychiatry, I56, 40-45.

DuRand, C., Burtka, G. J., Federman, E. J., et al (1995) A quarter century of suicide in a major urban jail: implications for community psychiatry. American Journal of Psychiatry, 152, 1077-1080.

Frottier, P., Frühwald, S., Ritter, K., et al (200I)

Deprivation versus Importation: ein Erklärungsmodell für die Zunahme von Suiziden in Haftanstalten. Fortschritte der Neurologie Psychiatrie, 69, 90-96.

Frottier, P., Fruehwald, S., Ritter, K., et al (2002a) Jailhouse Blues revisited. Social Psychiatry and Psychiatric Epidemiology, 37, 68-73.

Frottier, P., Matschnig, T., Benda, N., et al (2002b) Die letzte psychiatrische Anstalt. Recht und Psychiatrie, 20, 162-167.

Fruehwald, S., Frottier, P., Benda, N., et al (2002a) Psychosoziale Charakteristika von Suizidopfern in Gefängnissen. Wiener Klinische Wochenschrift, II4 69|-696.

Fruehwald, S., Frottier, P., Ritter, K., et al (2002b) Impact of overcrowding and legislational change on the incidence of suicide in custody: experiences in Austria, 1967-1996. International Journal of Law and Psychiatry, 25, $119-128$.
Fruehwald, S., Frottier, P., Matschnig, T., et al (2003) The relevance of previous suicide behaviour for prison suicide. European Psychiatry, 18, 161-165.

HM Chief Inspector of Prisons for England and Wales (1999) 'Suicide is Everyone's Concern' - A Thematic Review. London: Home Office.

Joukamaa, M. (1997) Prison suicide in Finland 1969-1992. Forensic Science International, 89, $167-174$

Laishes, J. (1997) Suicides in the correctional services of Canada. Crisis, 18, 157-162.

Landsberg, G. \& Morschauser, P. (2003) Issues in the prevention and detection of suicide potential in correctional facilities. In Principles and Practice of Forensic Psychiatry (2nd edn) (ed. R. Rosner), pp. 513-5I8. London: Arnold.

Marcus, P. \& Alcabes, P. (1993) Characteristics of suicides by inmates in an urban jail. Hospital and Community Psychiatry, 44, 256-261.

Ringel, E. (1969) Selbstmordverhütung (Suicide Prevention). Bern: Huber.

Rockett, I. R. H. \& McKinley Thomas, B. (1999) Reliability and sensitivity of suicide certification in higherincome countries. Suicide and Life-Threatening Behavior, 29, $|4|-149$.

Scottish Prison Service (2003) Suicide Risk Management and Custodial Care. An InterAgency Approach: 'Suicide is Everyone's Business'. Edinburgh: SPS (http: / /www.sps.gov.uk/keydocs/ suicide). 